\title{
JURNAL PENELITIAN DAN PENGEMBANGAN HUMANIORA
}

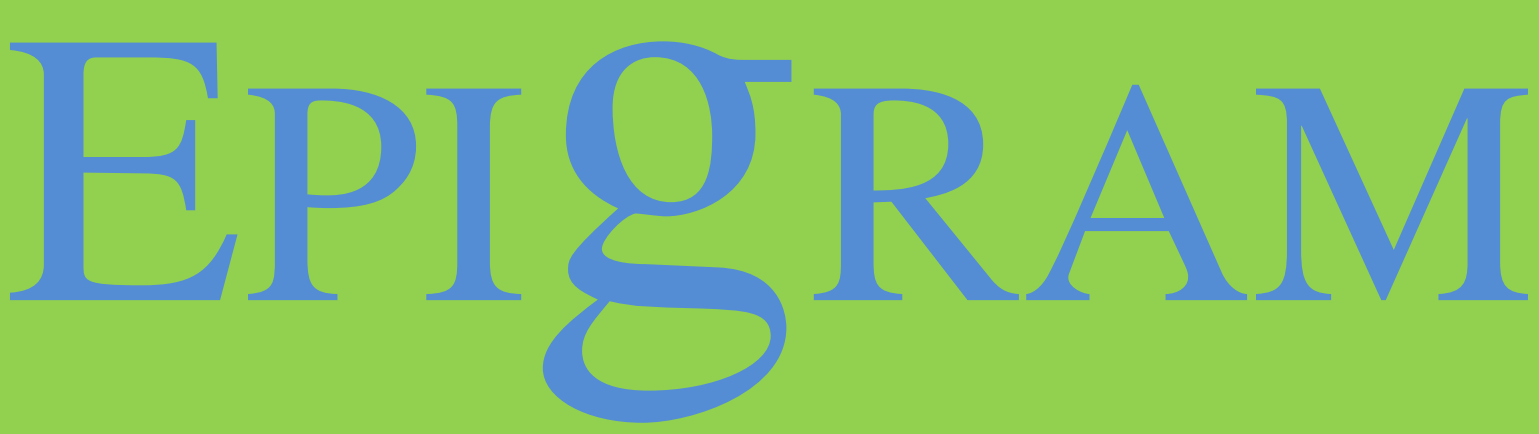

\section{VOLUME 16 NOMOR 2 OKTOBER 2019}

PENGEMBANGAN BAHAN AJAR MATEMATIKA BISNIS BERBASIS KOMPUTER UNTUK MAHASISWA JURUSAN AKUNTANSI POLITEKNIK NEGERI BALI

I Made Wijana, Anak Agung Putri Suardani, I Gede Made Karma

ANALISIS KEPUASAN PENGUNJUNG TERHADAP LAYANAN PERPUSTAKAAN POLITEKNIK $111-120$ NEGERI BALI

Ni Wayan Dewinta Ayuni, Wayan Hesadijaya Utthavi, AA. Istri Raka

INDONESIAN STUDENTS’ LISTENING ATTITUDES

$121-130$

Tribekti Maryanto Agustinus, Nur Rini, Mitchell Clark

ANALISIS KEBUTUHAN KOMPETENSI PEKERJA INDUSTRI KULIT/ALAS KAKI MENYONGSONG ERA INDUSTRI 4.0

Taukhid W Broto, Risang Pujiyanto

ANALISIS KEAKURATAN TERJEMAHAN TINDAK TUTUR DIREKTIF DALAM "SUBTITLE" DIALOG FILM THE MASK OF ZORRO

Lenny Brida, Mawarta Onida Sinaga

PENINGKATAN KETERAMPILAN BERBICARA BAHASA INGGRIS MELALUI MEDIA FILM

Wardah Hanafiah

KANTIN POLITEKNIK DILIHAT DARI PERILAKU MAHASISWA ADMINISTRASI NIAGA SEBAGAI KONSUMEN (Studi Kasus Pada mahasiswa Administrasi Niaga Politeknik Negeri Jakarta)

Azwar, Anwar Mustofa

PERSEPSI DOSEN TERHADAP PENGGUNAAN ICT DALAM PEMBELAJARAN BAHASA INGGRIS

Sari Puspita Dewi, Abdul Azis Abdillah, Nidia Sofa

KESADARAN BELA NEGARA PADA MAHASISWA

Minto Rahayu, Rita Farida, Asep Apriana

ANALISIS PERMASALAHAN PELAKSANAAN PRAKTIK KERJA LAPANGANMAHASISWA PROGRAM STUDI D-3 ADMINISTRASI BISNIS JURUSAN ADMINISTRASI NIAGA POLITEKNIK NEGERI JAKARTA

Ni Made Widhi Sugianingsih, Narulita Syarweni, Wahyudi Utomo

USING ANTCONC SOFTWARE AS ENGLISH LEARNING MEDIA: THE STUDENTS’ PERCEPTION Eri Ester Khairas

PENGARUH KUALITAS PELAYANAN TERHADAP LOYALITAS PELANGGAN MUJIGAE RESTO DEPOK

Yusthika Prasetya Probo Dewi, Iis Mariam, Menik Wijiyanti

PENGARUH CITRA MEREK DAN HARGA TERHADAP KEPUTUSAN PEMBELIAN MASKARA MAYBELLINE (STUDI KASUS PADA MAHASISWI ADMINISTRASI NIAGA POLITEKNIK NEGERI JAKARTA)

Sarah Fahira, Tuti Hartati, Hafniza Amir

EVALUASI TINGKAT KUALITAS PELAYANAN BIDANG KEMAHASISWAAN MENGGUNAKAN SERVEQUAL DI POLITEKNIK NEGERI JAKARTA

Fatimah, Darna, Ansori 

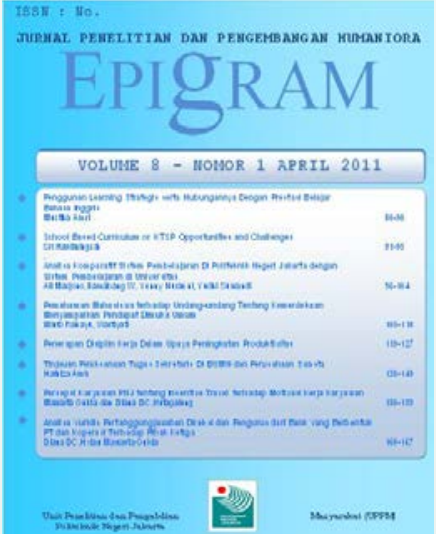

\section{Penanggung Jawab}

Direktur Politeknik Negeri Jakarta

\section{Ketua Dewan Redaksi}

Mawarta Onida

\section{Penyunting Ahli}

Wahyu Wibowo (UNAS)

Margaretha Hanita (LEMHANAS)

Any Noor (POLBAN)

lis Mariam (PNJ)

\section{Anggota Dewan redaksi \\ Ina Sukaesih \\ Minto Rahayu}

\section{Desain Cover}

Fitria Asfadayanti

\section{Pelaksana Tata Usaha Sugiyanto \\ Bayu Pratama Putra}

\section{PENGANTAR}

Pembaca yang terhormat,

Jurnal Epigram adalah jurnal yang memuat hasilpenelitian yang terkait dengan pengkajian dan pengembangan bidang humaniora. Jurnal ini terbit 2 kali dalam setahun, yaitu pada bulan April dan Oktober.

Jurnal Epigram edisi ini adalah epigram volume 16 nomor 2 Oktober 2019. Volume 16 ini memuat tiga belas artikel ilmiah sebagai hasil penelitian dosen Politeknik Negeri Jakarta dan beberapa dosen Perguran Tinggi diluar PNJ.

Artikel Pertama adalah artikel hasil penelitian yang ditulis oleh I Made Wijana, Anak Agung Putri Suardani, I Gede Made Karma dari Politeknik Negeri Bali dengan judul Pengembangan Bahan Ajar Matematika Bisnis Berbasis Komputer Untuk Mahasiswa Jurusan Akuntansi Politeknik Negeri Bali.

Artikel Kedua adalah Analisis Kepuasan Pengunjung Terhadap Layanan Perpustakaan Politeknik Negeri Bali, yang ditulis oleh Ni Wayan Dewinta Ayuni, Wayan Hesadijaya Utthavi, AA. Istri Raka dari Politeknik Negeri Bali.

Artikel Ketiga adalah artikel berbahasa Inggris hasil penelitian oleh Dosen Politeknik Negeri Semarang Tribekti Maryanto Agustinus, Nur Rini, Mitchell Clark yang berjudul Indonesian Students' Listening Attitudes.

Artikel Keempat adalah Analisis Kebutuhan Kompetensi Pekerja Industri Kulit/Alas Kaki Menyongsong Era Industri 4.0 oleh Taukhid W Broto, Risang Pujiyanto dari Politeknik ATK Yogyakarta.

Artikel kelima adalah artikel tentang Analisis Keakuratan Terjemahan Tindak Tutur Direktif Dalam “Subtitle” Dialog Film The Mask Of Zorro oleh Lenny Brida, Mawarta Onida Sinaga.

Artikel keenam adalah hasil penelitian tentang Peningkatan Keterampilan Berbicara Bahasa Inggris Melalui Media Film oleh Wardah Hanafiah.

Artikel ketujuh ditulis oleh Azwar, Anwar Mustofa yang menyajikan hasil penelitian dengan judul Kantin Politeknik Dilihat Dari Perilaku Mahasiswa Administrasi Niaga Sebagai Konsumen (Studi Kasus Pada Mahasiswa Administrasi Niaga Politeknik Negeri Jakarta).

Artikel Kedelapan adalah hasil penelitian tentang Persepsi Dosen Terhadap Penggunaan ICT Dalam Pembelajaran Bahasa Inggris yang dilaksanakan oleh Sari Puspita Dewi, Abdul Azis Abdillah, Nidia Sofa.

Artikel Kesembilan adalah Kesadaran Bela Negara Pada Mahasiswa oleh Minto Rahayu, Rita Farida, Asep Apriana.

Artikel Kesepuluh adalah hasil penelitian yang ditulis oleh Ni Made Widhi Sugianingsih, Narulita Syarweni, Wahyudi Utomo yang menyajikan judul Analisis Permasalahan Pelaksanaan Praktik Kerja Lapanganmahasiswa Program Studi D-3 Administrasi Bisnis Jurusan Administrasi Niaga Politeknik Negeri Jakarta.

Artikel Kesebelas adalah Using Antconc Software As English Learning Media: The Students' Perception oleh Eri Ester Khairas.

Artikel Keduabelas adalah hasil penelitian tentang Pengaruh Kualitas Pelayanan Terhadap Loyalitas Pelanggan Mujigae Resto Depok oleh Yusthika Prasetya Probo Dewi, Iis Mariam, Menik Wijiyanti.

Artikel Ketigabelas adalah Pengaruh Citra Merek Dan Harga Terhadap Keputusan Pembelian Maskara Maybelline (Studi Kasus Pada Mahasiswi Administrasi Niaga Politeknik Negeri Jakarta) oleh Sarah Fahira, Tuti Hartati dan Hafniza Amir.

Artikel Keempatbelas adalah Evaluasi Tingkat Kualitas Pelayanan Bidang Kemahasiswaan Menggunakan Servequal Di Politeknik Negeri Jakarta oleh Fatimah, Darna dan Ansori.

Ahli, Penyunting Pelaksana, Staf Pelaksana Tata Usaha, serta pihak lain yang tidak dapat penulis sebutkan satu persatu sehingga edisi ini dapat diterbitkan. Kami harapkan semoga jurnal edisi ini dapat memperkaya literature hasil penelitian bidang humaniora, dan semoga di masa yang akan datang Kami selaku tim editor dapat menampilkan hasil penelitian yang lebih baik.

Akhirnya, kami dewan redaksi mengucapkan selamat membaca dan menikmati kehadiran Epigram Volume 16 ini.

Ketua Dewan Redaksi

Alamat Redaksi

Sekretariat P3M Politeknik Negeri Jakarta

Gedung Direktorat Lt. 2.

Kampus Baru UI Depok 16425

E-mail : p3m@pnj.ac.id atau mawaronida@yahoo.com 